\title{
Altered translational fidelity of a Salmonella typhimurium LT2 mutant resistant to the aminoglycoside antibiotic neamine
}

\author{
DJordje Fira, Branka Vasiljević and Ljubisa Topisirovic* \\ Genetic Engineering Centre, Vojvode Stepe 283, PO Box 794, 11001 Belgrade, Yugoslavia
}

(Received 11 August 1989; revised 18 October 1989; accepted 26 October 1989)

\begin{abstract}
A neamine-resistant mutant of Salmonella typhimurium LT2 with altered translational fidelity was isolated. The phenomenon was expressed in severe restriction of amber suppressor activity in vivo as well as in decreased misreading of poly(U) RNA in vitro. The mutation conferring resistance to neamine was mapped at $72 \mathrm{~min}$ on the Salmonella genetic map, where some of the ribosomal genes have already been mapped. This location indicates that the neamine-resistant phenotype as well as an altered translational fidelity could be a consequence of an alteration of the ribosomal structure.
\end{abstract}

\section{Introduction}

A number of Escherichia coli mutants which are resistant to aminoglycoside antibiotics have been isolated during the last 15 years. Such mutants have an altered ribosomal structure and are of great help in understanding the mode of ribosomal functioning. Ribosomal mutants can be divided into two classes as far as translational fidelity is concerned. The first class consists of mutants showing increased translational fidelity, such as many streptomycin-resistant mutants (having altered ribosomal protein S12) (Gorini, 1974), one neamine-resistant mutant (altered ribosomal protein S17) (Bollen et al., 1975) and one gentamicin-resistant mutant (altered ribosomal protein L6) (Küchberger et al., 1979). These mutants have lower levels of misreading compared to wild-type bacteria and they show restrictive effects on suppressor activity.

Ribosomal ambiguity mutants belong to the second class. Mutants with altered protein S4 (Rosset \& Gorini, 1969) or S5 (Piepersberg et al., 1975; Cabezon et al., 1976) have decreased translational fidelity. Also, proteins S4 and S5 can diminish the restrictive action of protein S17 in double mutants (Topisirovic et al., 1977; Matkovic et al., 1980). Recently, E. coli mutants having an altered protein L7/L12, which showed decreased translational fidelity, were isolated (Kirsebom \& Isaksson, 1985; Kirsebom et al., 1986). It was also found that an altered form of elongation factor Tu (coded by the tuf $A$ gene in a kirromycin-resistant mutant of $E$. coli) shows a similar behaviour, giving increased misreading as well as suppression of nonsense codons in vivo (Tapio \& Isaksson, 1989).

In this paper, we describe the isolation and characterization of a neamine-resistant mutant of Salmonella typhimurium with altered translational fidelity. We were interested in finding out whether this mutant of $S$. typhimurium LT2 would have similar behaviour to the neamine-resistant mutant of $E$. coli. This mutant could also help in understanding the location and organization of ribosomal genes in S. typhimurium.

\section{Methods}

Bacterial strains. The strains of Salmonella typhimurium LT2 used in this work are described in Table 1.

Media. Nutrient Broth (NB; Difco) was used as a liquid medium to which $1.5 \%(\mathrm{w} / \mathrm{v})$ agar (NA; Difco) was added when used as a solid medium. The minimal medium (E) of Vogel \& Bonner (1956) solidified with $1.5 \%(w / v)$ agar was used. Neamine and streptomycin were added to NA medium to the final concentrations as indicated in Table 2.

Genetic experiments. (a) Mutagenesis by EMS was done as described by Dabbs (1978). Samples (0.1 ml) of treated cultures were plated on NA plates containing neamine $\left(100 \mu \mathrm{g} \mathrm{ml}^{-1}\right)$. Neamine-resistant mutants appeared after $2 \mathrm{~d}$ of incubation at $37^{\circ} \mathrm{C}$.

(b) Transductional crosses were done by using phages P22.HT105 and P22int-4. Samples $(0.1 \mathrm{ml})$ of phage stock prepared on donor cells and $0.1 \mathrm{ml}$ of recipient cells were plated on selective medium plates and incubated until transductants appeared. 
Table 1. List of bacterial strains used

\begin{tabular}{|c|c|c|}
\hline Strain & Genotype & Source \\
\hline $\begin{array}{l}\text { DB7155 } \\
\text { DB7155str }\end{array}$ & $\begin{array}{l}\text { hisC52am leuA414am supE20 } \\
\text { hisC52am leuA414am supE20, } \\
\text { rpsL201 }\end{array}$ & $\begin{array}{l}\text { D. Botstein, MIT, Cambridge, Mass, USA. } \\
\text { rpsL201 is transduced from SU } 453 \text { into DB7155 }\end{array}$ \\
\hline DBN100-5 & $\begin{array}{l}\text { hisC52am leuA414am supE20, } \\
\text { neaA1 }\end{array}$ & This paper \\
\hline DBA33 & $\begin{array}{l}\text { hisC52am leuA414am supE20, } \\
\text { aroE36 rpsE }\end{array}$ & $\begin{array}{l}\text { aro } E \text { and } r p s E \text { mutations are transduced from } \\
\text { TY78 into DB7155 }\end{array}$ \\
\hline $\begin{array}{l}\text { DBAS2 } \\
\text { DBAR1 }\end{array}$ & $\left\{\begin{array}{l}\text { Transductants from transduction } \\
\text { P22/DBN100-5 } \times \text { DBA33 }\end{array}\right.$ & This paper \\
\hline SU453 & $\begin{array}{l}\text { hisF1009 trpC2 metA22 rpsL201 } \\
\text { xylR1 }\end{array}$ & SGSC* \\
\hline $\begin{array}{l}\text { TY78 } \\
\text { SA1519 }\end{array}$ & $\begin{array}{l}\text { aroE36 rpsE } \\
\text { proAB47 } \text { arg } D 454\end{array}$ & $\begin{array}{l}\text { J. Davies, University of Wisconsin, Madison, USA. } \\
\text { SGSC* }\end{array}$ \\
\hline SA1749 & $\begin{array}{l}r f b-430 \text { fla-66 rpsL metA22 trpC2 } \\
\mathrm{H} 1^{\mathrm{b}} \mathrm{HZent} / \mathrm{F}^{\prime} \text { lacU281UAG }\end{array}$ & SGSC* \\
\hline $\begin{array}{l}\text { JL616 } \\
\text { LT1 }\end{array}$ & $\begin{array}{l}\operatorname{aroE} 65 \\
\operatorname{trp} 167 / \mathrm{F}^{\prime} 42\end{array}$ & $\begin{array}{l}\text { J. L. Ingraham, University of California, Davis, USA. } \\
\text { Laboratory collection }\end{array}$ \\
\hline
\end{tabular}

* Salmonella Genetic Stock Centre by courtesy of Dr K. E. Sanderson, University of Calgary, Alberta, Canada.

Table 2. In vivo characteristics of mutant DBN100-5 and transductants DBAS2 and DBARI

\begin{tabular}{|c|c|c|c|c|c|c|c|c|c|c|c|c|}
\hline \multirow[b]{3}{*}{ Strain } & \multirow{3}{*}{$\begin{array}{l}\text { Relevant } \\
\text { genotype* }\end{array}$} & \multicolumn{7}{|c|}{ Growth on: } & & & & \\
\hline & & \multirow{2}{*}{$\begin{array}{l}\text { Minimal } \\
\text { medium } †\end{array}$} & \multicolumn{6}{|c|}{ Rich medium $\ddagger$} & \multicolumn{4}{|c|}{ Support of P22 phage growth $\S$} \\
\hline & & & nea10 & nea20 & nea50 & neal00 & $\operatorname{str} 100$ & str 500 & H5 & $1^{-}$am 18 & $8^{-}$amN26 & 13-amH101 \\
\hline DB7155 & supE & + & - & - & - & - & - & - & + & + & - & + \\
\hline DB7155str & supE rpsL & - & - & - & - & - & + & + & + & - & - & + \\
\hline DBN100-5 & supE neaA & - & + & + & + & \pm & + & - & + & - & - & + \\
\hline DBAS2 & $\sup E$ & + & - & - & - & $=$ & - & - & + & + & - & + \\
\hline DBAR 1 & $\sup E$ neaA & - & + & + & + & \pm & + & - & + & - & - & + \\
\hline
\end{tabular}

* For other markers see the list of strains (Table 1).

$\dagger+$, growth after $24 \mathrm{~h}$ at $37^{\circ} \mathrm{C}$.

$\ddagger$ nea 10 to nea 100 and str 100 and str500 indicate the concentrations of neamine and streptomycin, respectively, used in the test $\left(\mu \mathrm{g} \mathrm{ml} \mathrm{m}^{-1}\right)$; \pm , growth after $72 \mathrm{~h}$ at $37^{\circ} \mathrm{C}$.

$\S+$, efficiency of plating close to $1.0 ;-$, efficiency of plating less than $10^{-7}$. Mutation $8^{-}$amN26 was used as a negative control; it cannot be suppressed by supE.

(c) Restriction assays were performed by spotting various amber mutants of phage P22 (P22am phages) (kindly provided by D. Botstein) at concentrations ranging from $10^{8}$ to $10^{2}$ phages $\mathrm{ml}^{-1}$ onto a lawn of bacteria spread on NA plates in $2.5 \mathrm{ml} 0.7 \%(\mathrm{w} / \mathrm{v})$ top agar.

Biochemical experiments. (a) $\beta$-Galactosidase activity was assayed according to Miller (1972).

(b) Misreading assays were done essentially as described by Pestka $e t$ al. (1975), using soluble fraction II prepared from neamine-sensitive $E$. coli as a source of elongation factors (Wood \& Berg, 1961) and total tRNA charged with $\left[{ }^{14} \mathrm{C}\right]$ phenylalanine or $\left[{ }^{14} \mathrm{C}\right]$ isoleucine (Ravel \& Shorey, 1971). Poly(U) RNA was used to test the misreading of ribosomes in vitro.

Neamine was kindly provided by Dr G. B. Whitfield of the Upjohn Company (Kalamazoo, Michigan, USA).

\section{Results}

\section{Resistance of mutant DBN100-5 to antibiotics}

We isolated a neamine-resistant mutant DBN100-5 of $S$. typhimurium LT2 after EMS-induced mutagenesis of strain DB7155 and selection for ability to grow in the presence of neamine $\left(100 \mu \mathrm{g} \mathrm{ml}^{-1}\right)$. The mutant was compared with the parental strain DB7155 and a streptomycin-resistant derivative (DB7155str) for resistance to neamine and streptomycin. It was able to grow repeatedly and efficiently at concentrations of up to 
$50 \mu \mathrm{g}$ neamine $\mathrm{ml}^{-1}$, whereas its growth was slower at $100 \mu \mathrm{g}$ neamine $\mathrm{ml}^{-1}$. Besides resistance to neamine, mutant DBN100-5 showed resistance to streptomycin, but the level of its resistance to streptomycin was much lower than that of DB7155str (Table 2).

\section{Restriction of suppressor activity in vivo}

Restriction of informational suppressor in vivo was tested using amber mutants of phage P22 (Winston et al., 1979). The growth of these mutants depends on the activity of an amber suppressor (supE) present in the recipient bacteria. If the suppressor activity is abolished, the phage will not be able to grow. Using this test, we compared the restriction pattern of the mutant DBN1005 with that of the strain DB7155str (carries the rpsL mutation which imposes a restriction on the supE activity). We found that the restriction patterns were exactly the same in these two mutants. In addition, both mutants DBN100-5 and DB7155str grew more slowly on minimal medium compared with the parental strain DB7155, indicating that suppression of hisam and leuam mutations is not fully efficient (Table 2). These results suggested that mutant DBN100-5 carries a mutation responsible for the restriction of supE activity.

In order to measure the in vivo level of restriction of supE activity, we introduced either $\mathrm{F}^{\prime}$ lac $^{+}$or $\mathrm{F}^{\prime}$ lacam episomes into strains DB7155, DB7155str and DBN1005 , and assayed for $\beta$-galactosidase. As shown in Table 3 , the level of $\beta$-galactosidase synthesis was lowest in the mutant DBN100-5 carrying F'lacam. This indicates that the mutation conferring the resistance to neamine could be responsible for the severe restriction of $\sup E$ activity in this mutant.

Keeping in mind that both the resistance to aminoglycoside neamine and the restriction of informational suppressor in $E$. coli are connected with an altered

Table 3. Restriction of supE activity measured by $\beta$-galactosidase assay

\begin{tabular}{|c|c|c|c|c|}
\hline \multirow[b]{2}{*}{ Strain } & \multirow{2}{*}{$\begin{array}{l}\text { Relevant } \\
\text { genotype* }\end{array}$} & \multicolumn{3}{|c|}{$\beta$-gal units in strain carrying: $\dagger$} \\
\hline & & $\mathrm{F}^{\prime} \mathrm{lac}^{+}$ & $F^{\prime}$ lacam & $\mathrm{F}^{\prime} \mathrm{lac}^{+} / \mathrm{F}^{\prime}$ lacam \\
\hline DB7155 & supE & $8 \cdot 348$ & $1 \cdot 785$ & $4 \cdot 68$ \\
\hline DB7155str & supE rpsL & $4 \cdot 283$ & 228 & $18 \cdot 79$ \\
\hline DBN100-5 & supE neaAl & 2.669 & 38 & $70 \cdot 24$ \\
\hline DBAS2 & supE & 5.851 & 1.657 & 3.54 \\
\hline DBAR1 & supE neaAI & $2 \cdot 503$ & 60 & $41 \cdot 72$ \\
\hline
\end{tabular}

* For other markers see the list of strains.

$\dagger \mathrm{F}^{\prime}$ lac ${ }^{+}$and $\mathrm{F}^{\prime}$ lacam episomes are introduced by conjugation of each strain with LT1 and SA1749, respectively, selecting for the ability of conjugants to grow on minimal medium supplemented with lactose, histidine and leucine. The $\beta$-galactosidase was assayed and $\beta$-gal units were calculated according to Miller (1972). ribosomal structure, at least in the mutants analysed so far (Bollen et al., 1975), all characteristics of $S$. typhimurium mutant DBN100-5 strongly suggested that it might be a ribosomal mutant also.

\section{Mapping of the neaA mutation}

Since most of the genes coding for the ribosomal proteins are located at $72 \mathrm{~min}$ of the $E$. coli genetic map (Bachmann \& Low, 1980) and some of the ribosomal protein genes have the same location on the $S$. typhimurium LT2 genetic map (Sanderson \& Roth, 1983), we investigated whether the neamine-resistance of the mutant DBN100-5 maps in the same region. Phage P22int-4, grown on DBN 100-5, was used to transduce the neamine-resistance character into different recipients. After analysis of the resulting transductants we conclude that a gene conferring resistance to neamine in mutant DBN100-5, designated neaAl, maps at 72 min on the genetic map (Fig. 1). Mapping data also demonstrated that neaAl and $r p s L$ mutations had different locations at the $72 \mathrm{~min}$ of the Salmonella chromosome.

In order to investigate any relationship between the mapped neaAl mutation and an altered translational fidelity of mutant DBN100-5, we constructed strain DBA33. This strain is an $a r o E^{-} s p c^{r}$ derivative of strain DB7155 obtained by cotransduction of $a r o E^{-}$and $s p c^{r}$ from strain TY78 into DB7155 selecting for spectinomycin-resistant transductants. It had the same characteristics as DB7155 with respect to sensitivity to neamine and translational fidelity.

We transduced strain DBA33 by P22. HT105 phages grown on DBN100-5, selecting for aro $E^{+}$transductants. Of 292 tested transductants, nine (class I) were sensitive to neamine and did not exhibit a restrictive phenotype, while seven transductants (class II) were resistant to neamine and had a restrictive phenotype (Fig. 2). Transductants DBAS2 and DBAR1 were chosen as representatives of class I and class II, respectively (Table 2 ). The $\beta$-galactosidase assay confirmed these findings since transductant DBAS2, carrying the $\mathrm{F}^{\prime} \mathrm{lac}^{+}$or $\mathrm{F}^{\prime}$ lacam episomes, had almost the same $\beta$-galactosidase activities as in the case of the parental strain DB7155, whereas $\beta$-galactosidase activity in transductant DBAR1 with the same episomes was very like that of the mutant DBN100-5 (Table 3). These results demonstrate that neamine resistance and restrictive phenotype could be cotransferred, suggesting that the neaAl mutation could be responsible for the behaviour of the mutant DBN1005. In addition to neamine resistance, transductants which inherited the neaAl mutation were also partially resistant to streptomycin. The level of their resistance to streptomycin was the same as that of the mutant DBN100-5 (Table 2). 


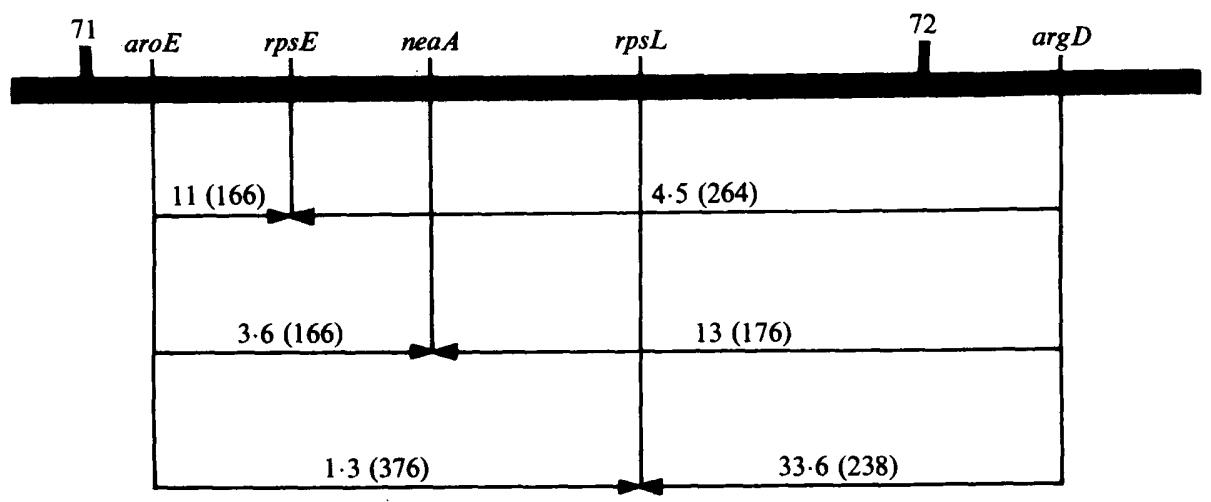

Fig. 1. Localization of neaAl mutation on the Salmonella chromosome. Phage P22int-4 was used for mapping and recipient strains were JL616 aroE65 and SA1519 proAB47 argD454. The numbers below the bold line are cotransduction frequencies (\%) and numbers in parentheses represent the numbers of transductants tested. Arrows indicate the markers which were screened in transductants. Gene designations are those of Sanderson \& Roth (1983).

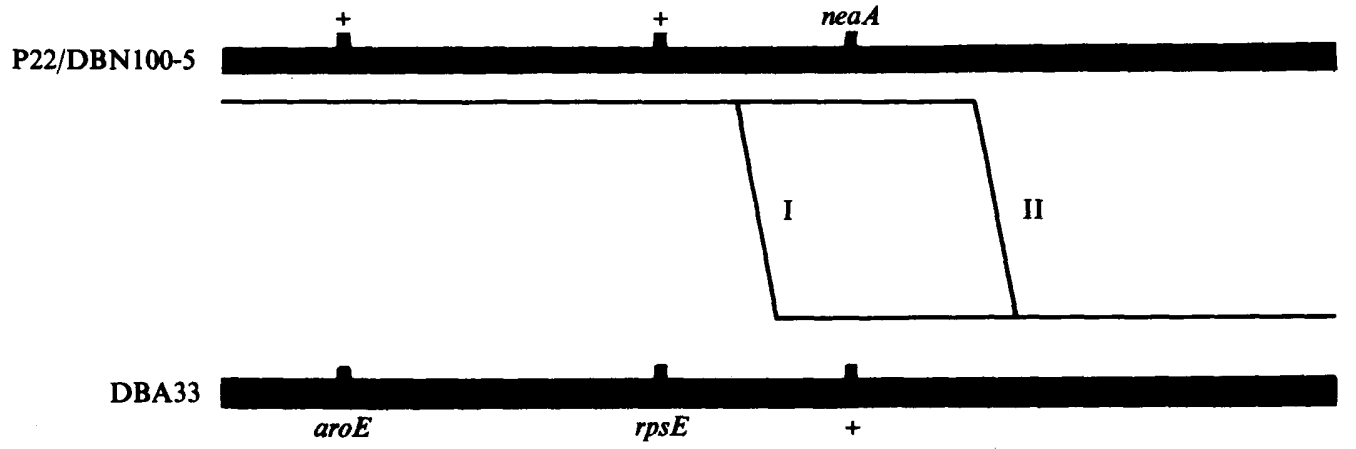

Fig. 2. Schematic presentation of transductions. Only relevant markers are shown. Phage P22.HT105 was used for transductions and aro $E^{+}$transductants were selected. Transductants resistant only to spectinomycin were isolated as well. They were not used in further analysis because they were identical in all aspects to the recipient strain DBA33.

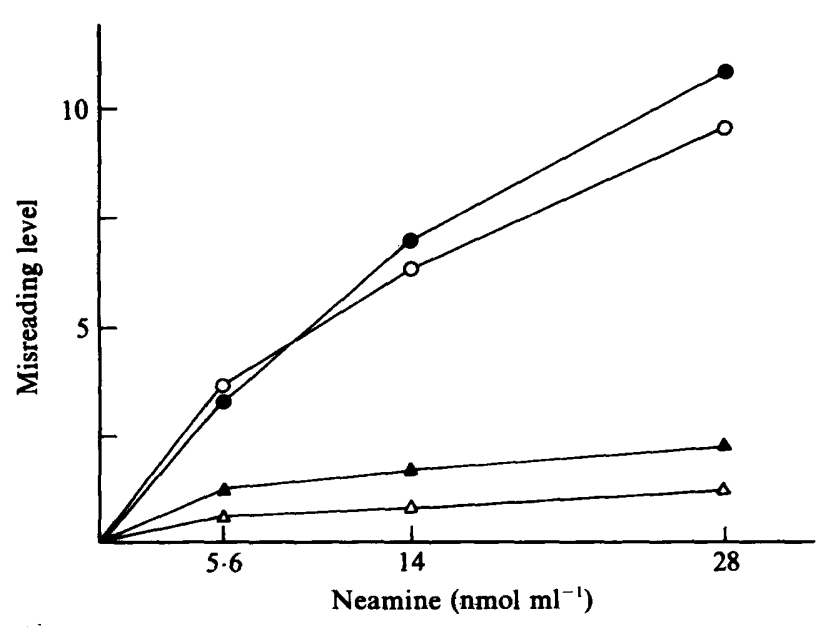

Fig. 3. Neamine-induced misreading of $70 \mathrm{~S}$ ribosomes from strains DB7155 (O), DBN100-5 ( $\triangle$ ), DBAS2 (๑) and DBAR1 (A). Poly(U) RNA was used to test the misreading of ribosomes in vitro. The misreading level is given as pmol $\left[{ }^{14} \mathrm{C}\right]$ isoleucine-tRNA incorporated in the presence of the antibiotic per 100 pmol [ ${ }^{14} \mathrm{C}$ lphenylalaninetRNA incorporated without drug. The misreading obtained in the absence of antibiotic was subtracted. Standard assay $(100 \mu l)$ contained $40 \mathrm{pmol} 70 \mathrm{~S}$ ribosomes and incorporated $137 \mathrm{pmol}\left[{ }^{14} \mathrm{C}\right]$ phenylalaninetRNA. Specific activities of $\left[{ }^{14} \mathrm{C}\right]$ phenylalanine-tRNA and $\left[{ }^{14} \mathrm{C}\right]$ isoleucine-tRNA were 106 c.p.m. and 154 c.p.m. pmol-1, respectively.

\section{Analysis of translational fidelity in vitro}

Taking all obtained data into consideration, we were interested in seeing whether ribosomes from the neamine-resistant $S$. typhimurium mutant DBN100-5 give an altered in vitro misreading compared to wild-type ribosomes. Therefore, we isolated high-salt-washed $70 \mathrm{~S}$ ribosomes from the parental strain DB7155, mutant DBN100-5 and transductants DBAS2 and DBAR1 and used poly(U) RNA to test their ability to give in vitro misreading. As can be seen in Fig. 3, 70S ribosomes from the neamine-sensitive transductant DBAS2 give a misreading level similar to that of $70 \mathrm{~S}$ ribosomes isolated from the neamine-sensitive parental strain DB7155. However, the misreading levels of $70 \mathrm{~S}$ ribosomes from the transductant DBAR1 and the neamine-resistant mutant DBN100-5 were very similar.

\section{Discussion}

Since Salmonella and $E$. coli belong to the same family of bacteria, we were interested to see whether resistance of 
Salmonella to neamine would have characteristics similar to that found in E. coli. It is already known that resistance to some aminoglycosides differs between these two bacteria. For instance, Salmonella is more tolerant towards spectinomycin than $E$. coli (Yamada \& Davis, 1971). Neamine-resistant mutants of $E$. coli have been isolated and characterized and neamine resistance shown to be the consequence of alteration of ribosomal protein S17 (Bollen et al., 1975) or both S5 and S12 (DeWilde et al., 1975). The genes coding for all these proteins are located in the $72 \mathrm{~min}$ region of the $E$. coli genetic map where most of ribosomal genes are mapped (Bachmann \& Low, 1980).

Transductional analysis of the neamine-resistant mutant DBN100-5 of $S$. typhimurium revealed that the mutation conferring resistance was located in the $72 \mathrm{~min}$ region of the Salmonella genetic map where mutations determining resistance to streptomycin and spectinomycin have already been mapped (Sanderson \& Roth, 1983). This position for neaAl suggests that DBN100-5 is a ribosomal mutant.

Mutant DBN100-5 showed severe restriction of suppressor activity in vivo, since it did not support the growth of phage P22 amber mutants and showed a lower level of $\beta$-galactosidase synthesis in spite of the fact that it carries an active supE gene. This should normally suppress amber mutations present in phage P22 mutants or the $l a c Z$ gene. Similar results concerning restriction of suppressor activity have been obtained with a neaA mutant of $E$. coli (Topisirovic et al., 1977).

The mutant DBN100-5 showed decreased misreading in vitro which is in agreement with the results obtained in vivo. In that respect, mutant DBN100-5 was similar to the neaA mutant of $E$. coli having an altered ribosomal protein $\mathbf{S 1 7}$, which gives altered translational fidelity. Unfortunately, two-dimensional PAGE analysis of ribosomal proteins isolated from both subunits of either mutant DBN100-5 and neamine-resistant transductant DBAR1 did not show any difference in comparison with the parental, neamine-sensitive strain DB7155 (data not shown). However, since high-salt-washed ribosomes isolated from a resistant mutant or transductant were used for the in vitro misreading assay, and other components came from a sensitive strain, we could infer that mutant DBN100-5 is a ribosomal one.

This work was supported by grant no. 1.41.5 from Science Fund of the Republic of Serbia.

\section{References}

Bachian,, B. J. \& Low, K. B. (1980). Linkage map of Escherichia coli K-12. Microbiological Reviews 44, 1-56.
Bollen, A., Cabezon, T., DeWilde, M., Villaroel, R. \& Herzog, A. (1975). Alteration of ribosomal protein $S 17$ by mutation linked to neamine resistance in E. coli. Journal of Molecular Biology 99, 795-806.

Cabezon, T., Herzog, A., DeWilde, M., Villaroel, R. \& Bollen, A. (1976). Cooperative control of translational fidelity by ribosomal proteins in E. coli. III. A ram mutation in the structural gene for protein S5 (rpsE). Molecular and General Genetics 144, 59-62.

DABBs, E. R. (1978). Mutational alterations in 50 proteins of $E$. coli ribosome. Molecular and General Genetics 165, 73-78.

DeWilde, M., Cabezon, T., Herzog, A. \& Bollen, A. (1975). Cooperative control of translational fidelity by ribosomal proteins in Escherichia coli. I. Properties of ribosomal mutants whose resistance to neamine is the cumulative effect of two distinct mutations. Molecular and General Genetics 142, 19-33.

GORINI, L. (1974). Streptomycin and misreading of the genetic code. In Ribosomes, pp. 791-803. Edited by M. Nomura, A. Tissières \& P. Lengyel. Cold Spring Harbor, NY: Cold Spring Harbor Laboratory.

KIRSEBOM, L. A. \& IsAKsSon, L. A. (1985). Involvement of ribosomal protein L7/L12 in control of translational accuracy. Proceedings of the National Academy of Sciences of the United States of America 82, 717-721.

Kirsebom, L. A., Amons, R. \& Isaksson, L. A. (1986). Primary structures of mutationally altered ribosomal protein $L 7 / \mathrm{L} 12$ in control of translational accuracy. European Journal of Biochemistry 156, 669-675.

Kôchberger, R., Piepersberc, W., Petzet, A., Buckel, P. \& Böck, A. (1979). Alteration of ribosomal protein L6 in gentamicin resistant strains of Escherichia coli. Effects on translational fidelity of protein synthesis. Biochemistry 18, 187-193.

Matkovic, B., Herzog, A., Bollen, A. \& Topisirovic, L. (1980). Translational fidelity in Escherichia coli: antagonistic effects of neaA and $\operatorname{ramC}$ gene products on the ribosome function. Molecular and General Genetics 179, 135-139.

Miller, J. H. (1972). Experiments in Molecular Genetics. Cold Spring Harbor, NY: Cold Spring Harbor Laboratory.

Pestra, S., Marchal, R. \& Nirenberg, M. W. (1975). RNA code words and protein synthesis. V. Effect of the streptomycin on the formation of ribosome sRNA complexes. Proceedings of the National Academy of Sciences of the United States of America 53, 639-646.

Pitpersberg, W., BöCK, A. \& WittmanN, H. G. (1975). Effect of different mutations in the ribosomal protein $S 5$ of $E$. coli on translational fidelity. Molecular and General Genetics 140, 91-100.

RAVEL, J. \& SHOREY, R. A. L. (1971). GTP-dependent binding of aminoacyl-tRNA to Escherichia coli ribosomes. Methods in Enzymo$\log y$ 20, 306-316.

ROsSET, R. \& GORINI, L. (1969). A ribosomal ambiguity mutation. Journal of Molecular Biology 39, 95-101.

SANDERSON, K. E. \& ROTH, J. (1983). Linkage map of Salmonella typhimurium. Microbiological Reviews 47, 410-453.

TAPIO, S. \& Isaksson, L. A. (1989). Antagonistic effects of mutant elongation factor $\mathrm{Tu}$ and ribosomal protein $\mathrm{S} 12$ on control of translational accuracy, suppression and cellular growth. Biochemie 70, 273-281.

Topisirovic, L., Villaroel, R., DeWilde, M., Herzog, A., CabezON, T. \& BOLLEN, A. (1977). Translational fidelity in E. coli: contrasting role of neaA and ramA gene products in the ribosome functioning. Molecular and General Genetics 151, 89-94.

VOGEL, H. J. \& BONNER, D. M. (1956). Acetylornithinase of Escherichia coli: partial purification and some properties. Journal of Biological Chemistry 218, 97-106.

WINSTON, F., BotSTEIN, D. \& MiLLER, J. H. (1979). Characterization of amber and ochre suppressors in Salmonella typhimurium. Journal of Bacteriology 137, 433-439.

WOOD, W. B. \& BERG, P. (1962). The effect of enzymatically synthesized ribonucleic acid on amino acid incorporation by soluble protein-ribosome system from Escherichia coli. Proceedings of the National Academy of Sciences of the United States of America 48, 94-104.

YAMADA, T. \& DAvis, J. (1971). A genetic and biochemical study of streptomycin- and spectinomycin-resistance in Salmonella typhimurium. Molecular and General Genetics 110, 197-210. 